\title{
Dyslexia and the Integration of Sensory Cues into Motor Action
}

\author{
José A. Barela1,2, Paulo Barbosa de Freitas1, André Rocha Viana3, Milena Razuk1 \\ ${ }^{1}$ Graduate Program, Human Movement Sciences, Institute of Physical Activity and Sport Sciences, Cruzeiro do \\ Sul University, São Paulo, Brazil \\ ${ }^{2}$ Institute of Biosciences, São Paulo State University, Rio Claro, Brazil \\ ${ }^{3}$ Department of Physical Therapy, University of Illinois at Chicago, Illinois, USA \\ Email: jose.barela@cruzeirodosul.edu.br
}

Received 19 August 2014; revised 15 September 2014; accepted 12 October 2014

Copyright (C) 2014 by authors and Scientific Research Publishing Inc.

This work is licensed under the Creative Commons Attribution International License (CC BY). http://creativecommons.org/licenses/by/4.0/

(c) (i) Open Access

\section{Abstract}

Besides difficulties in mastering literacy, dyslexic children also show poor postural control that might be related to how sensory cues coming from different sensory channels are integrated and trigger proper motor activity. The purpose of this study was to review the body of literature about the functioning of the postural control system in dyslexic children and understand how they use sensory information to produce motor actions. It has been demonstrated that dyslexic children sway more than non-dyslexic ones. Studies have shown that although manipulation of vision and somatosensory information provided by a moving room and a moving touch bar, respectively, induced correspondent body sway in dyslexic children, their postural responses to such manipulations were less coherent as compared to non-dyslexic children. When dyslexic children applied higher force on the moving bar, however, coherence between body sway and sensory manipulations was similar for dyslexic and non-dyslexic children. Finally, in the absence of peripheral visual cues, induced body sway in dyslexic children was temporally delayed regarding visual stimulus. Taken together, these results indicate that poor postural control in dyslexic children is related to impairments in the manner sensory information is acquired and used to produce postural responses. The need of dyslexic children to apply more force on the touch bar to improve coherence between sensory stimulus and body sway, together with the fact that in conditions in which visual cues were less informative, dyslexic children took longer to process sensory stimuli and produce motor responses, suggests that dyslexic children are more dependent on the quality of sensory cues.

\section{Keywords}

Vision, Somatosensory, Posture, Perception, Postural Control 


\section{Introduction}

It has been noticed for many years that dyslexic children also show signs of poor performance in motor skills. However, the underlying mechanisms shared by sensorimotor deficits and literacy problems in dyslexic children remain to be uncovered. Nicolson, Fawcett and Dean (2001) suggested that the apparent underpinning causes for both motor control and reading difficulties in dyslexia may be due to a mild impairment of development and functioning of the cerebellum. This theoretical explanation suggests that a cerebellar dysfunction in dyslexia impairs not only motor control and coordination, but also limits the extent to which cognitive skills such as reading can be mastered.

The mild cerebellar insult, which would impair the ability of acquiring behavioral automaticity, would require that dyslexic individuals have to put more efforts consciously while reading, writing, and performing other tasks such as reaching and maintaining a desired and stable postural orientation (Fawcett \& Nicolson, 2004). Based upon this assumption, we have further suggested that poor performance in postural control shown by dyslexic individuals might be related to how sensory cues, coming from different sensory channels, are integrated and trigger proper motor activity (Barela, Dias, Godoi, Viana, \& Freitas Jr., 2011). Hence, the systematic investigation of the sensorimotor coupling could lead to a better understanding of the genesis of dyslexia. Therefore, the aim of this study was to examine the functioning of the postural control system in dyslexic children and to explore how they use sensory information to produce motor actions.

\section{Postural Control and Dyslexia}

Many studies have shown that dyslexic children and adults perform worse than non-dyslexic peers in postural control tasks (Brookes, Tinkler, Nicolson, \& Fawcett, 2010; Fawcett \& Nicolson, 1999; Fawcett, Nicolson, \& Dean, 1996; Moe-Nilssen, Helbostad, Talcott, \& Toennessen, 2003; Patel, Magnusson, Lush, Gomez, \& Fransson, 2010; Pozzo et al., 2006; Rochelle, Witton, \& Talcott, 2009; Stoodley, Fawcett, Nicolson, \& Stein, 2005; Vieira, Quercia, Michel, Pozzo, \& Bonnetblanc, 2009). The commonest task employed to examine postural control system performance is to stay as steady as possible in upright stance for a certain period of time and the indication of worse performance in dyslexic children than non-dyslexic ones is based on the fact that dyslexic children and adults sway with larger magnitude than their normal reader' peers. However, a larger body sway in dyslexic than non-dyslexic children is not always observed (Patel et al., 2010; Rochelle et al., 2009; Stoodley, Fawcett, Nicolson, \& Stein, 2006). Thus, the opinion that dyslexic children present an altered postural control system is not unanimous and is motive of debate (Fawcett, 2011; Viholainen et al., 2011). Looking at a different perspective, we would like to suggest that, as observed for older adults (Prioli, Cardozo, de Freitas Jr., \& Barela, 2006), different results might be due to different assessment procedures employed, such as the task and the performance variables used to quantity stability or balance during a postural task.

Despite of the possible methodological and procedural differences used to examine postural control in dyslexic children, we would like to suggest that such task might constitute an important strategy to explore the underlying mechanisms determining poor reading performance in dyslexic children. In order to control the balance of a multi-segmented body in a specific orientation, one needs to sustain a close relationship between sensory information and motor activity (Horak \& Macpherson, 1996). Sensory cues coming from multiple sources need to furnish a complete and accurate identification of the relative position of the many body segments in the environment and the forces acting on them. Based upon these sensory cues, the central nervous system elaborates a frame of reference, regarding the desired and the real body position and, finally, produces specific and appropriate muscle activation in order to adjust body orientation.

The required interplay between sensory information and motor activity in postural control is not trivial. For instance, children take several years to achieve adult-like performance (Barela, Sanches, Lopes, Razuk, \& Moraes, 2011; Figura, Cama, Capranica, Guidetti, \& Pulejo, 1991; Godoi \& Barela, 2008; Rinaldi, Polastri, \& Barela, 2009), mostly because of the sensory integration required to perform such task (Godoi \& Barela, 2008; Peterson, Christou, \& Rosengren, 2006). Moreover, performance deterioration is also observed due to the aging process affecting sensory integration (Toledo \& Barela, 2014). Finally, postural control performance not only requires an intricate relationship between sensory information and motor activity (Barela, Jeka, \& Clark, 2003), but also that such relationship happens automatically as people have a short period of time to identify the relative body segment position and the forces acting on the body in order to produce activation of specific muscles to achieve or to maintain a desired position. We would like to suggest that, taking all the appropriate cautions, 
reading and writing shared much of the above described mechanism. Reading and writing are also sensorimotor tasks in such way that one needs to acquire precise information regarding the letters and produce correspondent and appropriate muscle activation in order to control the vocal cords to produce the sound or the hand to write the letters (Berninger, Nielsen, Abbott, Wijsman, \& Raskind, 2008; Sumner, Connelly, \& Barnett, 2014). If this is the case, dyslexia also is related to sensorimotor integration as most of our daily live activities.

\section{Vision and Touch Manipulation in Postural Control}

One strategy to carefully examine the relationship between sensory information and motor action is to manipulate a specific channel or source of sensory information and observe the motor consequences of it (Schöner, Dijkstra, \& Jeka, 1998). One ingenious way of doing so in postural control is to manipulate the optical flow, as first used by Lee and collaborators (Lee \& Aronson, 1974; Lishman \& Lee, 1973), while the remaining sensory cues are kept unaltered. We and many others have employed a moving room in order to manipulate visual information and induce corresponding body sway in infants (Barela, Godoi, Freitas Jr., \& Polastri, 2000; Bertenthal, Rose, \& Bai, 1997), children (Rinaldi et al., 2009; Schmuckler, 1997), and adults (Barela, Barela, Rinaldi, \& Toledo, 2009). More importantly, this corresponding and coherent body sway is induced without deliberate knowledge regarding the postural oscillation (Stoffregen, Hove, Schmit, \& Bardy, 2006) and if such knowledge is provided, the coupling established between visual information and body sway is altered (Barela et al., 2009; Barela et al., 2014; Freitas Jr. \& Barela, 2004).

Such strategy was recently considered as unique in order to examine the relationship between visual information and body sway in dyslexic children (Barela, Dias et al., 2011). We have showed that dyslexic children are influenced by visual manipulation as their peers. For instance, Figure 1 depicts a typical time series of the moving room displacement and body sway of a dyslexic child during a 60-second trial (Figure 1(a)). As it can be observed, induced body sway was correspondent to the visual manipulation: as the moving room oscillated back and forward, body sway also occurred back and forward. Based upon these results, we suggested that dyslexic children use visual information to postural control with the same underlying process as non-dyslexic children (Barela, Dias et al., 2011).

Despite the similarity in the underlying process of using visual information to control posture, dyslexic children differed from non-dyslexic ones in several aspects (Barela, Dias et al., 2011). First, without any visual manipulation and during the maintenance of upright stance, dyslexic children swayed with larger magnitude than non-dyslexic children. Second, with visual manipulation, dyslexic children still swayed more than non-dyslexic ones, and they showed a less coherent and more variable relationship between visual information and body sway than non-dyslexic children. Based upon these results, we suggested that dyslexic children despite employing the same underpinning mechanisms in using visual information to postural control, they could not perform as well as non-dyslexic children with the relationship between visual information and body sway. Dyslexic children are capable of using visual information to control posture, but they show poorer and more variable performance that is related to how sensory cues are integrated into motor activity (Barela, Dias et al., 2011).

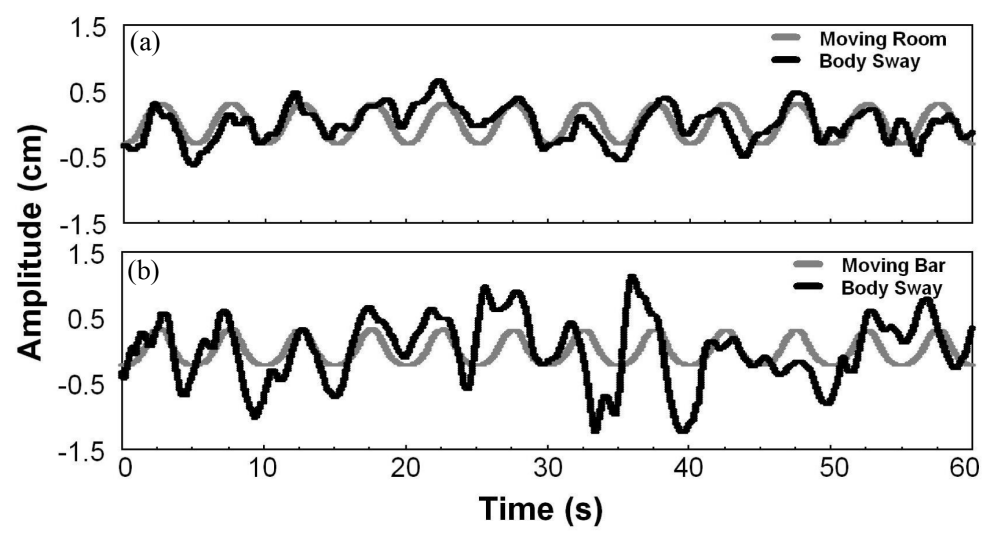

Figure 1. Trunk sway and moving room (top panels) and moving bar (bottom panels) displacement time-series for a non-dyslexic participant in the anterior-posterior direction. 
Finally, because the relationship between vision and sway in controlling posture in the moving room is achieved without an active and conscious sensorimotor involvement, with participants swaying with the visual manipulation without knowing about it, we suggested that dyslexic children would have difficulties in becoming skillful due to difficulties in automatically integrating sensory information into motor action even in an everyday task as standing upright (Barela, Dias et al., 2011). Again, dyslexic children can perform the required task of standing upright, but they do it not as well as their peers do.

The above results and explanation seem to be appropriated to shed light into an intriguing issue related to dyslexia causes. However, it is well-known that visual impairments might be related to dyslexia cause (Facoetti, Paganoni, \& Lorusso, 2000; Facoetti, Turatto, Lorusso, \& Mascetti, 2001; Qian \& Bi, 2014; Stein, 2003). For instance, difference in the use of visual information to control motor activity could be due to different reasons. Thus, further investigation related to how sensory cues, other than visual ones, would be useful and thoughtful in order to examine if these observed differences were specific to vision or applicable to any other sensory modality. Jeka and colleagues (Jeka, Oie, Schöner, Dijkstra, \& Henson, 1998; Jeka, Ribeiro, Oie, \& Lackner, 1998; Jeka, Schöner, Dijkstra, Ribeiro, \& Lackner, 1997) have developed an experimental paradigm that mimics the moving room manipulation by asking individuals to touch lightly (less than $1 \mathrm{~N}$ of applied force) a moveable plate using their fingertips while maintaining upright stance. Similarly to the moving room, the moving touch bar induces body sway coherently to bar movement (Jeka, Oie et al., 1998; Jeka, Ribeiro et al., 1998; Jeka et al., 1997). Moreover, body sway due to light touch might also be induced without any participant's conscious involvement.

Employing the light touch moving paradigm, we investigated how dyslexic children not only use sensory cues from the fingertip, but also how sensory conflicting cues, vision and somatosensory, were resolved and used to control posture (Viana, Razuk, Freitas J., \& Barela, 2013). Dyslexic children and non-dyslexic children were able to couple to the sensory cues coming from lightly touching a moving bar, displaying coherent and correspondent body sway (Figure 1(b)). Body sway induction due to light touch in non-dyslexic children had previously been observed (Barela et al., 2003), but this study was pioneer regarding assessing dyslexic children. As observed in other condition, dyslexic children swayed with larger magnitude than non-dyslexic children in all the conditions employed in the study. Such result is in agreement with many other studies (Brookes et al., 2010; Moe-Nilssen et al., 2003; Pozzo et al., 2006; Stoodley et al., 2005), showing that dyslexic children show poor postural control. Moreover, again less coherent and more variable relationship between sensory cues, vision and fingertip somatosensory, and body sway were observed. Such results suggested that dyslexic children might have difficulties in coupling sensory cues coming from different modalities and motor action, specially in multisensory conditions, resulting in a postural control that is characterized by larger sway magnitude and more variability (Viana et al., 2013).

Interestingly, more variable performance in dyslexic children is not only observed in posture, since visuomotor processing in isometric force exertion visually guided by feedback is also characterized by similar variability and poorer performance when compared to non-dyslexic children (de Freitas, Pedao, \& Barela, 2014). Again, the functioning structure of hand force coordination was not different comparing dyslexic and non-dyslexic children, but only the fine and precise adjustments, which are dependent of precise visual cues, were affected in dyslexic children. Thus, based upon the observed results regarding postural control and visually guided force control, it was suggested that multisensory information integration is slightly affected in dyslexic children when performing motor tasks.

\section{Dyslexic Performance and Quality of Sensory Information}

An intriguing observation coming from few studies is that dyslexic children seem to be more affected by the quality of the available sensory cues. For instance, bigger letters and larger inter-letter spacing attenuate reading differences between dyslexic and non-dyslexic children (Zorzi et al., 2012). Similarly, shorter lines in which words are displayed facilitate reading in dyslexic children in which they increase the reading speed and reduce the number of regressive saccades (Schneps et al., 2013). Such striking results, at least for us, indicate and provide meaning for an important issue regarding possible underlying processes related to dyslexia. If dyslexic individuals can have their performance improved, reducing the difference to non-dyslexic children, this means that they have the underpinning structure to produce similarly to non-dyslexic the required behavior. Such suggestion corroborates previous suggestion that dyslexic children, for example, show the underlying mechanism to use visual information to control body sway (Barela, Dias et al., 2011; Viana et al., 2013) and to produce force 
accurately (de Freitas et al., 2014). Similarly, dyslexic children also are capable to read and write, indicating that the basic mechanisms required to perform such tasks are there, but their performance is still slightly different (Stoodley \& Stein, 2011, 2013). Again, dyslexic children can perform the required task (read, stand upright, use visual cues, etc.) and if they are affected by the quality of available sensory cues, we can explain how sensory cues are integrated into the motor activation required to perform the task.

Several studies have showed that dyslexic children display different eye behavior (Kapoula \& Bucci, 2007; Kapoula, Gaertner, \& Matheron, 2012) while performing, for example, postural tasks. Employing the light touch paradigm to examine the use of sensory cues to postural control in dyslexic children (Viana et al., 2013) also allowed us to observe that dyslexic children, in using cues from the fingertip touching the bar, need to applied a slight higher amount of force than non-dyslexic children (Viana et al., 2013). Although children were instructed and allowed to apply up to $1 \mathrm{~N}$ of force on the bar, average applied force level was around $0.4 \mathrm{~N}$, as it can observed in Figure 2, which were similar to other children's study (Barela et al., 2003). More important, however, is that applying a slight higher force level, dyslexic children perform similarly to non-dyslexic children. Therefore, dyslexic children require better sensory cues to enhance the quality of sensory information furnished by these cues and, in doing so, improve their behavioral performance.

If the above suggestion is correct, then we could also affect dyslexic children performance by degrading the quality or structure of sensory cues, worsening dyslexic children's performance. Recently, Razuk and Barela (2014) manipulated visual stimulus characteristics, during upright stance, which led to changes in the dyslexic children's postural control performance. Specifically, removing peripheral visual cues when the scenario was stationary led to more detrimental performance in the postural control of dyslexic compared to non-dyslexic children (Razuk \& Barela, 2014). Furthermore, in the moving room condition and with no peripheral visual cues, dyslexic children still displayed correspondent body sway but, again, with a much weaker coupling compared to non-dyslexic children. Taken together, these results indicate that dyslexic children are more dependent than non-dyslexic children on peripheral visual cues in order to control upright stance. Thus, if sensory cues are manipulated in order to enhance sensory information, dyslexic children improve their performance (Schneps et al., 2013; Viana et al., 2013; Zorzi et al., 2012), but if the opposite occurs, dyslexic children are affected the most (Razuk \& Barela, 2014).

\section{Sensory Integration Dynamics}

Adaptation is a signature of flexible and skillful behavior even in simple daily tasks. To stand still, cues from

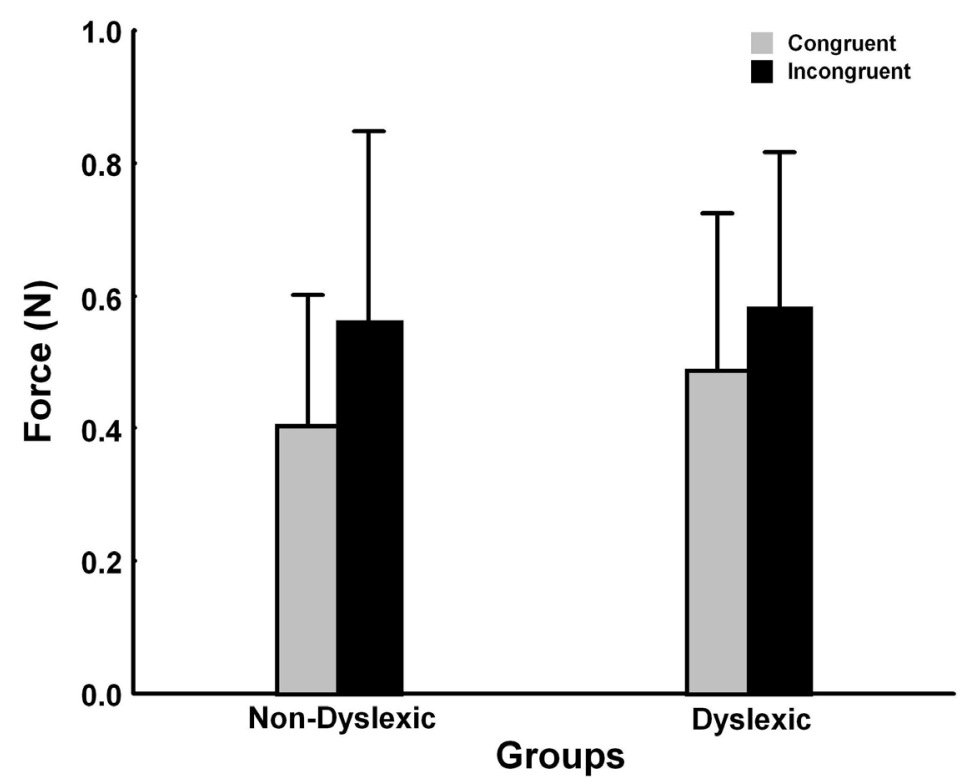

Figure 2. Mean vertical fingertip forces applied for dyslexic and non-dyslexic children when the moving room and the moving bar were moved simultaneously, in the same direction (congruent) and in opposite direction (incongruent). 
visual, vestibular, and somatosensory systems must be integrated to properly furnish knowledge about the relative body position and the forces acting on the body (Horak \& Macpherson, 1996), which is constantly changing. Many studies have established that such changes are partially driven by adaptively re-weighting sensory information (Horak \& Macpherson, 1996; Oie, Kiemel, Barela, \& Jeka, 2005; Peterka, 2002; Polastri, Barela, Kiemel, \& Jeka, 2012) in such way that one needs to identify coherent relationship between the acquired inputs and the action performed but also to skillfully modify this relationship as the environmental conditions and demands change.

It seems that dyslexic children have difficulties in dealing with such changes in the available sensory cues (Barela, Dias et al., 2011; Razuk \& Barela, 2014; Viana et al., 2013) and, therefore, have difficulties in getting accustomed to slight changes in sensory cues. It is important to mention that such suggestion does not mean that dyslexic children are not capable of adapting but that they might have a slight impairment in such mechanism. An intriguing result from our recent study (Razuk \& Barela, 2014) supports this suggestion. Figure 3 depicts the relative phase between the moving room position and body sway of dyslexic and non-dyslexic children. Dyslexic children presented a temporal delay between the moving room position and the induced body sway in the central vision condition (no peripheral visual cues) which differs from the non-dyslexic children who did not show such temporal delay between the full and central vision conditions. Basically, relative phase values around zero degree indicate that children are oscillating with the moving room with virtually no time delay. In the central vision condition, dyslexic children lagged behind the position of the moving room approximately 250 milliseconds, differently than the full vision condition and then non-dyslexic children (Razuk \& Barela, 2014).

Lagging behind the position of the room, in this case, is an indicative that dyslexic children needs longer time to process the available visual cues, but only in the condition of central vision, in which no peripheral cues were available, since not such difference was observed in the full vision condition. In taking longer to process the available and changed sensory cues, dyslexic children might be compromised in quality, more variability and not as precise as other may perform. This suggestion is very important as it may be directly related to the reading problems experienced by dyslexic children. Dyslexic children need longer time to process the available stimuli coming from multiple sensory channels and, consequently, their reading and writing fluency is compromised. Such problem may become more evident in conditions in which the sensory cues do not convey strong sensory information. When sensory cues are improved and information is enhanced, performance might be improved. It is interesting that difficulty in processing sensory cues has also been suggested to underlie some of the possible difficulties in children with developmental coordination disorder (Woei-Nan, Kiemel, Jeka, \& Clark, 2012).

Despite the fact that much more is needed to uncover the possible causes and the underlying mechanisms of dyslexia, it seems that the sensorimotor relationship understanding might shed some light into these issues. Stoodley and Stein (2011) acknowledge that successful reading involves the integration of sensory cues (visual and auditory) and, motor activity and that dyslexic can accomplish it, but not as accurate and

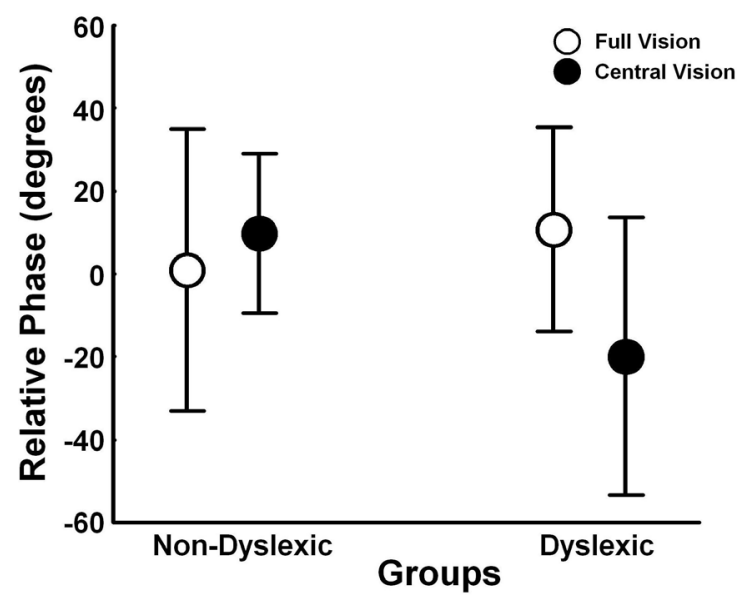

Figure 3. Mean relative phase values between the moving room position and body sway for dyslexic and nondyslexic children with full and central vision. 
adaptably as non-dyslexic. We might add that this is the case regarding postural control and other motor task as well, in which dyslexic children just perform slightly different due to difficulties in accommodating and processing quickly the available sensory cues in order to obtain complete information of the environment furnishing an appropriate basis for precise and accurate motor action.

\section{Acknowledgements}

We are grateful to the children and parents who gave their time and effort to participate in this study.

\section{References}

Barela, A. M., Barela, J. A., Rinaldi, N. M., \& Toledo, D. R. D. (2009). Influence of Imposed Optic Flow Characteristics and Intention on Postural Responses. Motor Control, 13, 119-129.

Barela, J. A., Dias, J. L., Godoi, D., Viana, A. R., \& Freitas Jr., P. B. (2011). Postural Control and Automaticity in Dyslexic Children: The Relationship between Visual Information and Body Sway. Research in Developmental Disabilities, 32, 1814-1821. http://dx.doi.org/10.1016/j.ridd.2011.03.011

Barela, J. A., Godoi, D., Freitas Jr., P., \& Polastri, P. F. (2000). Visual Information and Body Sway Coupling in Infants during Sitting Acquisition. Infant Behavior \& Development, 23, 285-297. http://dx.doi.org/10.1016/S0163-6383(01)00045-5

Barela, J. A., Jeka, J. J., \& Clark, J. E. (2003). Postural Control in Children: Coupling to Dynamic Somatosensory Information. Experimental Brain Research, 150, 434-442.

Barela, J. A., Sanches, M., Lopes, A. G., Razuk, M., \& Moraes, R. (2011). Use of Monocular and Binocular Visual Cues for Postural Control in Children. Journal of Vision, 11, 1-8. http://dx.doi.org/10.1167/11.12.10

Barela, J. A., Weigelt, M., Polastri, P. F., Godoi, D., Aguiar, S. A., \& Jeka, J. J. (2014). Explicit and Implicit Knowledge of Environment States Induce Adaptation in Postural Control. Neuroscience Letters, 566, 6-10. http://dx.doi.org/10.1016/j.neulet.2014.02.029

Berninger, V. W., Nielsen, K. H., Abbott, R. D., Wijsman, E., \& Raskind, W. (2008). Writing Problems in Developmental Dyslexia: Under-Recognized and Under-Treated. Journal of School Psychology, 46, 1-21. http://dx.doi.org/10.1016/j.jsp.2006.11.008

Bertenthal, B. I., Rose, J. L., \& Bai, D. L. (1997). Perception-Action Coupling in the Development of Visual Control of Posture. Journal of Experimental Psychology: Human Perception and Performance, 23, 1631-1643. http://dx.doi.org/10.1037/0096-1523.23.6.1631

Brookes, R. L., Tinkler, S., Nicolson, R. I., \& Fawcett, A. J. (2010). Striking the Right Balance: Motor Difficulties in Children and Adults with Dyslexia. Dyslexia, 16, 358-373. http://dx.doi.org/10.1002/dys.420

de Freitas, P. B., Pedao, S. T., \& Barela, J. A. (2014). Visuomotor Processing and Hand Force Coordination in Dyslexic Children during a Visually Guided Manipulation Task. Developmental Disabilities Research, 35, 2352-2358.

http://dx.doi.org/10.1016/j.ridd.2014.06.002

Facoetti, A., Paganoni, P., \& Lorusso, M. L. (2000). The Spatial Distribution of Visual Attention in Developmental Dyslexia. Experimental Brain Research, 132, 531-538. http://dx.doi.org/10.1007/s002219900330

Facoetti, A., Turatto, M., Lorusso, M. L., \& Mascetti, G. G. (2001). Orienting of Visual Attention in Dyslexia: Evidence for Asymmetric Hemispheric Control of Attention. Experimental Brain Research, 138, 46-53. http://dx.doi.org/10.1007/s002210100700

Fawcett, A. J. (2011). Balance and Reading Are Separate Symptoms of Dyslexia. Developmental Medicine Child Neurology, 53, 294-295. http://dx.doi.org/10.1111/j.1469-8749.2010.03886.x

Fawcett, A. J., \& Nicolson, R. I. (1999). Performance of Dyslexic Children on Cerebellar and Cognitive Tests. Journal of Motor Behavior, 31, 68-78. http://dx.doi.org/10.1080/00222899909601892

Fawcett, A. J., Nicolson, R. I., \& Dean, P. (1996). Impaired Performance of Children with Dyslexia on a Range of Cerebellar Tasks. Annals of Dyslexia, 46, 259-283.

Fawcett, A. J., \& Nicolson, R. I. (2004). Chapter 2: Dyslexia: The Role of the Cerebellum. In G. Reid, \& A. J. Fawcett (Eds.), Dyslexia in Context: Research, Policy and Practice (pp. 35-58). London: Whurr Publishers Ltd.

Figura, F., Cama, G., Capranica, L., Guidetti, L., \& Pulejo, C. (1991). Assessment of Static Balance in Children. The Journal of Sports Medicine and Physical Fitness, 31, 235-242.

Freitas de Freitas Jr., P. B., \& Barela, J. A. (2004). Postural Control as a Function of Self- and Object-Motion Perception. Neuroscience Letters, 369, 64-68. http://dx.doi.org/10.1016/j.neulet.2004.07.075

Godoi, D., \& Barela, J. A. (2008). Body Sway and Sensory Motor Coupling Adaptation in Children: Effects of Distance Manipulation. Developmental Psychobiology, 50, 77-87. http://dx.doi.org/10.1002/dev.20272 
Horak, F. B., \& Macpherson, J. M. (1996). Postural Orientation and Equilibrium. In L. B. Rowell, \& J. T. Sheperd (Eds.), Handbook of Physiology, Section 12. Exercise: Regulation and Integration of Multiple Systems (pp. 255-292). New York: Oxford University Press.

Jeka, J. J., Oie, K. S., Schöner, G., Dijkstra, T., \& Henson, E. (1998). Adaptive Velocity and Position Coupling of Postural Sway to Somatosensory Drive. Journal of Neurophysiology, 79, 1661-1674.

Jeka, J. J., Ribeiro, P., Oie, K., \& Lackner, J. R. (1998). The Structure of Somatosensory Information for Human Postural Control. Motor Control, 2, 13-33.

Jeka, J. J., Schöner, G., Dijkstra, T., Ribeiro, P., \& Lackner, J. R. (1997). Coupling of Fingertip Somatosensory Information to Head and Body Sway. Experimental Brain Research, 113, 475-483. http://dx.doi.org/10.1007/PL00005600

Kapoula, Z., \& Bucci, M. P. (2007). Postural Control in Dyslexic and Non-Dyslexic Children. Journal of Neurology, 254, 1174-1183. http://dx.doi.org/10.1007/s00415-006-0460-0

Kapoula, Z., Gaertner, C., \& Matheron, E. (2012). Spherical Lenses and Prisms Lead to Postural Instability in Both Dyslexic and Non Dyslexic Adolescents. PLoS ONE, 7, e46739. http://dx.doi.org/10.1371/journal.pone.0046739

Lee, D. N., \& Aronson, E. (1974). Visual Proprioceptive Control of Standing in Human Infants. Perception and Psychophysics, 15, 529-532. http://dx.doi.org/10.3758/BF03199297

Lishman, J. R., \& Lee, D. N. (1973). The Autonomy of Visual Kinaesthesis. Perception, 2, 287-294. http://dx.doi.org/10.1068/p020287

Moe-Nilssen, R., Helbostad, J. L., Talcott, J. B., \& Toennessen, F. E. (2003). Balance and Gait in Children with Dyslexia. Experimental Brain Research, 150, 237-244.

Nicolson, R. I., Fawcett, A. J., \& Dean, P. (2001). Developmental Dyslexia: The Cerebellar Deficit Hypothesis. Trends in Neurosciences, 24, 508-511. http://dx.doi.org/10.1016/S0166-2236(00)01896-8

Oie, K. S., Kiemel, T., Barela, J. A., \& Jeka, J. J. (2005). 5.24 The Dynamics of Sensory Reweighting: A Temporal Symmetry. Gait \& Posture, 21, S29. http://dx.doi.org/10.1016/S0966-6362(05)80099-2

Patel, M., Magnusson, M., Lush, D., Gomez, S., \& Fransson, P. A. (2010). Effects of Dyslexia on Postural Control in Adults. Dyslexia, 16, 162-174.

Peterka, R. J. (2002). Sensorimotor Integration in Human Postural Control. Journal of Neurophysiology, 88, 1097-1118.

Peterson, M. L., Christou, E., \& Rosengren, K. S. (2006). Children Achieve Adult-Like Sensory Integration during Stance at 12-Years-Old. Gait \& Posture, 23, 455-463. http://dx.doi.org/10.1016/j.gaitpost.2005.05.003

Polastri, P. F., Barela, J. A., Kiemel, T., \& Jeka, J. J. (2012). Dynamics of Inter-Modality Re-Weighting during Human Postural Control. Experimental Brain Research, 223, 99-108. http://dx.doi.org/10.1007/s00221-012-3244-Z

Pozzo, T., Vernet, P., Creuzot-Garcher, C., Robichon, F., Bron, A., \& Quercia, P. (2006). Static Postural Control in Children with Developmental Dyslexia. Neuroscience Letters, 403, 211-215. http://dx.doi.org/10.1016/j.neulet.2006.03.049

Prioli, A. C., Cardozo, A. S., de Freitas de Freitas Jr., P. B., \& Barela, J. A. (2006). Task Demand Effects on Postural Control in Older Adults. Human Movement Science, 25, 435-446. http://dx.doi.org/10.1016/j.humov.2006.03.003

Qian, Y., \& Bi, H. Y. (2014). The Visual Magnocellular Deficit in Chinese-Speaking Children with Developmental Dyslexia. Frontiers in Psychology, 5, 692. http://dx.doi.org/10.3389/fpsyg.2014.00692

Razuk, M., \& Barela, J. A. (2014). Dyslexic Children Suffer from Less Informative Visual Cues to Control Posture. Research in Developmental Disabilities, 35, 1988-1994. http://dx.doi.org/10.1016/j.ridd.2014.03.045

Rinaldi, N. M., Polastri, P. F., \& Barela, J. A. (2009). Age-Related Changes in Postural Control Sensory Reweighting. Neuroscience Letters, 467, 225-229. http://dx.doi.org/10.1016/j.neulet.2009.10.042

Rochelle, K. S., Witton, C., \& Talcott, J. B. (2009). Symptoms of Hyperactivity and Inattention Can Mediate Deficits of Postural Stability in Developmental Dyslexia. Experimental Brain Research, 192, 627-633. http://dx.doi.org/10.1007/s00221-008-1568-5

Schmuckler, M. A. (1997). Children's Postural Sway in Response to Low- and High-Frequency Visual Information for Oscillation. Journal of Experimental Psychology: Human Perception and Performance, 23, 528-545. http://dx.doi.org/10.1037/0096-1523.23.2.528

Schneps, M. H., Thomson, J. M., Sonnert, G., Pomplun, M., Chen, C., \& Heffner-Wong, A. (2013). Shorter Lines Facilitate Reading in Those Who Struggle. PLoS ONE, 8, e71161. http://dx.doi.org/10.1371/journal.pone.0071161

Schöner, G., Dijkstra, T. M. H., \& Jeka, J. J. (1998). Action-Perception Patterns Emerge from Coupling and Adaptation. Ecological Psychology, 10, 323-346. http://dx.doi.org/10.1080/10407413.1998.9652688

Stein, J. (2003). Visual Motion Sensitivity and Reading. Neuropsychologia, 41, 1785-1793. http://dx.doi.org/10.1016/S0028-3932(03)00179-9

Stoffregen, T. A., Hove, P., Schmit, J., \& Bardy, B. G. (2006). Voluntary and Involuntary Postural Responses to Imposed 
Optic Flow. Motor Control, 10, 24-33.

Stoodley, C. J., \& Stein, J. F. (2011). The Cerebellum and Dyslexia. Cortex, 47, 101-116. http://dx.doi.org/10.1016/j.cortex.2009.10.005

Stoodley, C. J., \& Stein, J. F. (2013). Cerebellar Function in Developmental Dyslexia. Cerebellum, 12, 267-276. http://dx.doi.org/10.1007/s12311-012-0407-1

Stoodley, C. J., Fawcett, A. J., Nicolson, R. I., \& Stein, J. F. (2005). Impaired Balancing Ability in Dyslexic Children. Experimental Brain Research, 167, 370-380. http://dx.doi.org/10.1007/s00221-005-0042-X

Stoodley, C. J., Fawcett, A. J., Nicolson, R. I., \& Stein, J. F. (2006). Balancing and Pointing Tasks in Dyslexic and Control Adults. Dyslexia, 12, 276-288. http://dx.doi.org/10.1002/dys.326

Sumner, E., Connelly, V., \& Barnett, A. L. (2014). The Influence of Spelling Ability on Handwriting Production: Children with and without Dyslexia. Journal of Experimental Psychology: Learning, Memory, and Cognition, 40, 1441-1447. http://dx.doi.org/10.1037/a0035785

Toledo, D. R., \& Barela, J. A. (2014). Sensory and Motor Differences between Young and Older Adults: Somatosensory Contribution to Postural Control. Revista Brasileira de Fisioterapia, 14, 267-275. http://dx.doi.org/10.1590/S1413-35552010000300004

Viana, A. R., Razuk, M., Freitas Jr., P. B., \& Barela, J. A. (2013). Sensorimotor Integration in Dyslexic Children under Different Sensory Stimulations. PLoS ONE, 8, e72719. http://dx.doi.org/10.1371/journal.pone.0072719

Vieira, S., Quercia, P., Michel, C., Pozzo, T., \& Bonnetblanc, F. (2009). Cognitive Demands Impair Postural Control in Developmental Dyslexia: A Negative Effect That Can Be Compensated. Neuroscience Letters, 462, 125-129. http://dx.doi.org/10.1016/j.neulet.2009.06.093

Viholainen, H., Aro, M., Ahonen, T., Crawford, S., Cantell, M., \& Kooistra, L. (2011). Are Balance Problems Connected to Reading Speed or the Familial Risk of Dyslexia? Developmental Medicine Child Neurology, 53, 350-353. http://dx.doi.org/10.1111/j.1469-8749.2010.03856.x

Woei-Nan, B., Kiemel, T., Jeka, J., \& Clark, J. E. (2012). Development of Multisensory Reweighting Is Impaired for Quiet Stance Control in Children with Developmental Coordination Disorder (DCD). PLoS ONE, 7, e40932.

Zorzi, M., Barbiero, C., Facoetti, A., Lonciari, I., Carrozzi, M., Montico, M. et al. (2012). Extra-Large Letter Spacing Improves Reading in Dyslexia. Proceedings of the National Academy of Sciences of the United States of America, 109, 1145511459. http://dx.doi.org/10.1073/pnas.1205566109 
Scientific Research Publishing (SCIRP) is one of the largest Open Access journal publishers. It is currently publishing more than 200 open access, online, peer-reviewed journals covering a wide range of academic disciplines. SCIRP serves the worldwide academic communities and contributes to the progress and application of science with its publication.

Other selected journals from SCIRP are listed as below. Submit your manuscript to us via either submit@scirp.org or Online Submission Portal.
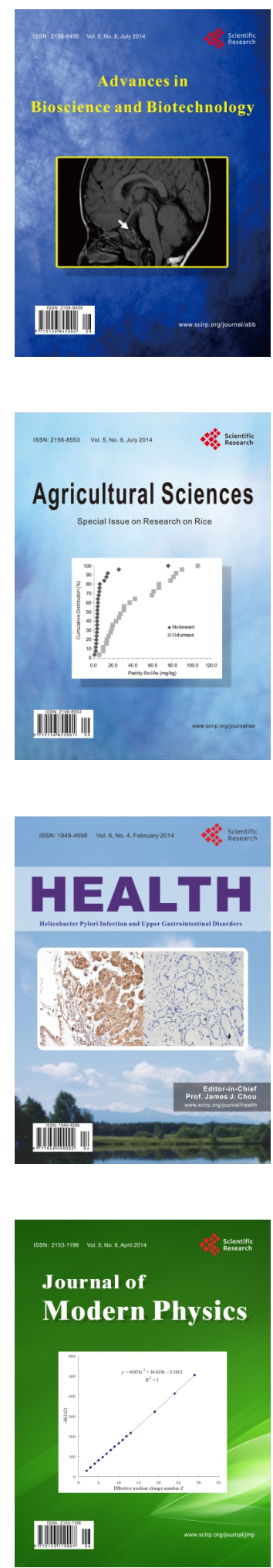
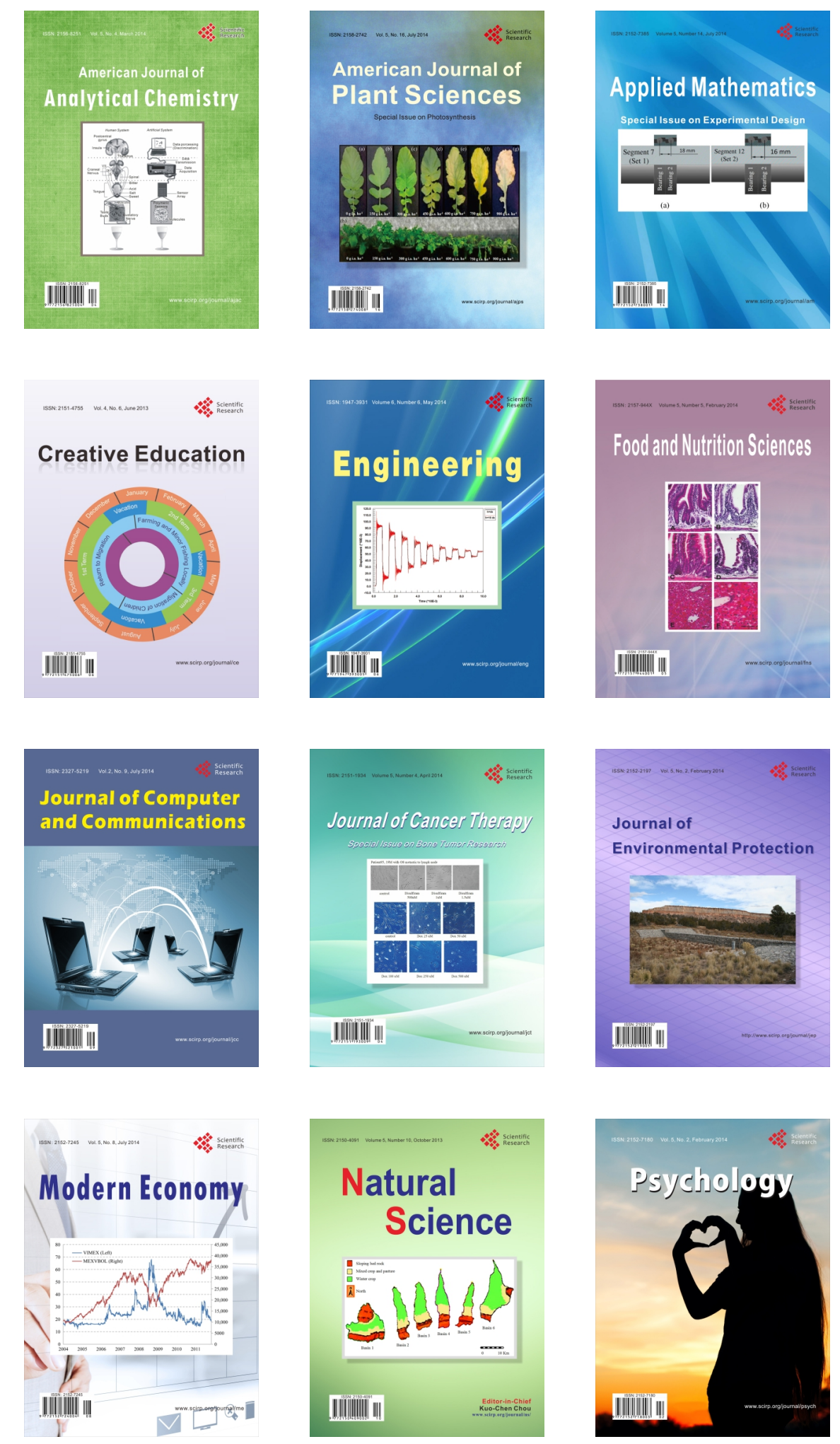